\title{
COVID-19's Financial Impact on Primary Care Clinicians and Practices
}

\author{
Melissa K. Filippi, PhD, MPH, Elisabeth Callen, PhD, GStat, Ann Wade, BS, BJ, \\ Megan Coffman, John M. Westfall, MD, Yalda Jabbarpour, MD, \\ Christina M. Hester, PhD, MPH, and Jennifer Carroll, MD, MPH
}

Introduction: Coronavirus disease 2019 (COVID-19) disrupted and undermined primary care delivery. The goal of this study was to examine the financial impacts the pandemic has had on primary care clinicians and practices.

Metbods: The American Academy of Family Physicians National Research Network and the Robert Graham Center distributed weekly surveys from March 27, 2020, through June 15, 2020, to a network of more than 1960 physicians. Responses to the question, "Could you please tell us about any financial impact the COVID-19 pandemic has had on your practice, if any?" were analyzed using a grounded theory approach of qualitative analysis. The number of unique respondents who answered the financial impact question totaled 461 over the 12 weeks.

Results: Severe declines in patient visits, causing drastic revenue reductions, greatly impacted the ability to serve patients. Primary care clinicians and practices experienced significant changes in several areas about financial implications: patient visits, financial strain, staffing and telehealth.

Discussion: Preliminary findings revealed that even with Coronavirus Aid, Relief, and Economic Security Act, also known as CARES Act, funding, business viability remains questionable for some primary care practices.

Conclusions: Low patient visits directly resulted in decreased revenues, which in turn, impacted staffing decisions and fueled telehealth implementation. It is difficult to predict whether patient visits will increase after June. Alternate payment models could provide some financial stability and address business viability. (J Am Board Fam Med 2021;34:489-497.)

Keywords: Alternate Payment Model, COVID-19, Economic Impact, Family Physicians, Financial Impact, Pandemics, Patient Visits, Primary Care, Telehealth, Workforce

\section{Introduction}

COVID-19's unprecedented economic impact on the global scale ${ }^{1,2}$ and within the United States ${ }^{3-5}$ has been profound. Models have predicted that the financial impact of COVID-19 on primary care practices could result in devastating increases in primary care shortage areas as practices are

This article was externally peer reviewed.

Submitted 24 September 2020; revised 28 January 2021; accepted 28 January 2021.

From the American Academy of Family Physicians National Research Network, Leawood, KS (MKF, EC, AW, $\mathrm{CMH}, \mathrm{JC})$; Robert Graham Center for Policy Studies, Washington, DC (MC, JMW, YJ); Department of Family Medicine, University of Colorado, Aurora, CO (JC).

Funding: None.

Conflict of interest: None.

Corresponding author: Melissa K. Filippi, PhD, 11400 Tomahawk Creek Pkwy Leawood, KS 66211 (E-mail: mfilippi@aafp.org). forced to close. ${ }^{6}$ This is particularly troublesome as primary care is the first line of defense for patient care in the US health care system. Our objective was to examine the financial impact the COVID-19 pandemic has had on primary care clinicians and their practices.

\section{Methods}

The American Academy of Family Physicians (AAFP) National Research Network and the Robert Graham Center conducted weekly surveys beginning on March 27, 2020, to determine the immediate and long-term impacts of COVID-19 on primary care clinicians and inform ways to mitigate those impacts. The project received AAFP Institutional Review Board (IRB) approval. Each survey was open for 4 days and respondents were sent weekly invitations to 
Figure 1. Number of Times a Unique Participant Has Participated.

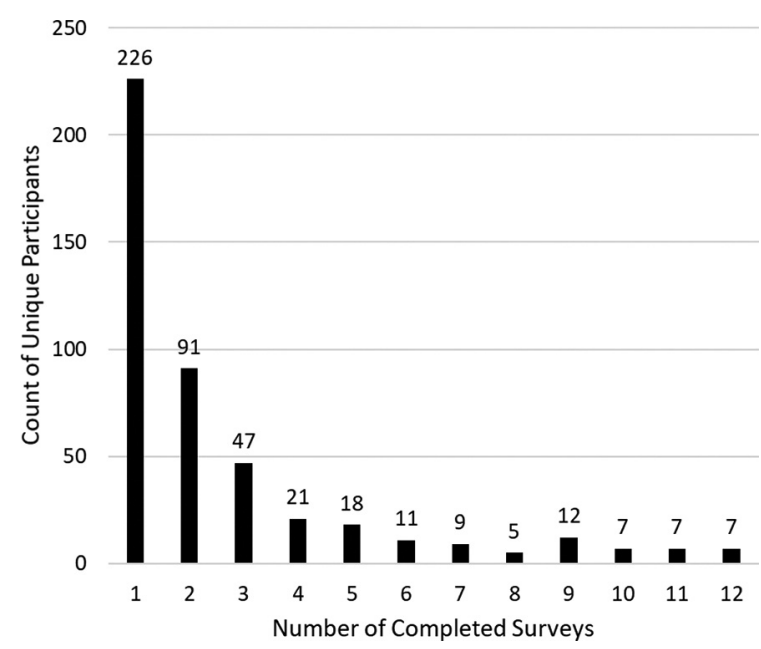

complete the survey. While the AAFP National Research Network has over 2300 registered members, our weekly surveys were distributed to only those members who have e-mail addresses on file, which was slightly over 1960 members (See Figure 1 for the number of times a respondent took the survey). Also, the survey was distributed using an anonymous link to AAFP National Research Network partners. Respondents' specialty and practice type information is summarized in Table 1 and respondent locations are provided in Figure 2. AAFP National Research Network members, by definition, sign up to be part of the research, though members' participation varies among projects. This distinction differentiates our respondents from other studies with respondents who are unaffiliated with a pre-established research network. ${ }^{7-17}$ Weekly surveys had between 5 and 8 questions and took less than 5 minutes to complete. Respondents did not receive compensation for participating in the survey. In each weekly survey, recurring questions appeared regarding the financial impact of the pandemic, how respondents were treating patients with symptoms consistent with COVID-19, as well as questions regarding clinicians' mental health, and a unique weekly question. Questions were in the format of select one, multiple-choice, checkbox, or slider, but the financial impact question required a written response. For this article, the following results focus solely on the open-ended question, "Could you please tell us about any financial impact the COVID19 pandemic has had on your practice, if any?" We report on the first 12 weeks' responses dating from March 27 through June 15, 2020 (Table 2).

Responses were analyzed using a grounded theory approach of qualitative analysis. ${ }^{18}$ Responses were reviewed and inductively coded by the first author. A coding category list was reviewed by the second and third authors to ensure the categories were appropriate for the data (Table 3). While the number of respondents changed each week, the categories that emerged reflect the respondents' personal- and practice-related financial concerns. Table 3 reports categories by week. Darker shaded boxes represent a higher number of times a category was mentioned. The primary reviewer wrote the themes and 2 other reviewers (EC, AW) reviewed and revised accordingly. Exemplary quotes were selected based on reviewer consensus; these are inserted and labeled within the text below and posted on the Robert Graham Center's website. ${ }^{19-30}$

\section{Results}

Over the 12 weeks, there were 461 unique respondents. Slightly under half of the respondents $(n=226$;

Table 1. Respondents' Specialty and Practice Type Affiliation, $(\mathrm{n}=461)$

\begin{tabular}{|c|c|}
\hline & $\mathrm{n}(\%)$ \\
\hline \multicolumn{2}{|l|}{ Specialty } \\
\hline Family medicine & $312(67.7)$ \\
\hline Other & $20(4.3)$ \\
\hline Behavioral health & $8(1.7)$ \\
\hline General internal medicine & $7(1.5)$ \\
\hline Emergency medicine & $4(0.9)$ \\
\hline Dental & $1(0.2)$ \\
\hline Missing & $109(23.6)$ \\
\hline \multicolumn{2}{|l|}{ Practice Type } \\
\hline Primary care only & $132(28.6)$ \\
\hline $\begin{array}{l}\text { Multi-specialty group (primary and specialty } \\
\text { physicians) }\end{array}$ & $34(7.4)$ \\
\hline Academic practice & $34(7.4)$ \\
\hline Other & $28(6.1)$ \\
\hline Academic center-based residency program & $26(5.6)$ \\
\hline Community-based residency program & $25(5.4)$ \\
\hline Integrated health & $23(5.0)$ \\
\hline Federally Qualified Health Center (FQHC) & $21(4.6)$ \\
\hline Rural health clinic & $20(4.3)$ \\
\hline Affiliated with academic medical center & $19(4.1)$ \\
\hline Community Health Center (CHC) & $10(2.2)$ \\
\hline Fellowship program & $3(0.7)$ \\
\hline FQHC Look-Alike (FQHC-LA) & $3(0.7)$ \\
\hline
\end{tabular}


Figure 2. Locations of Respondents $(\mathrm{n}=\mathbf{2 6 8})$. Note: A total of 193 participants have missing locations.

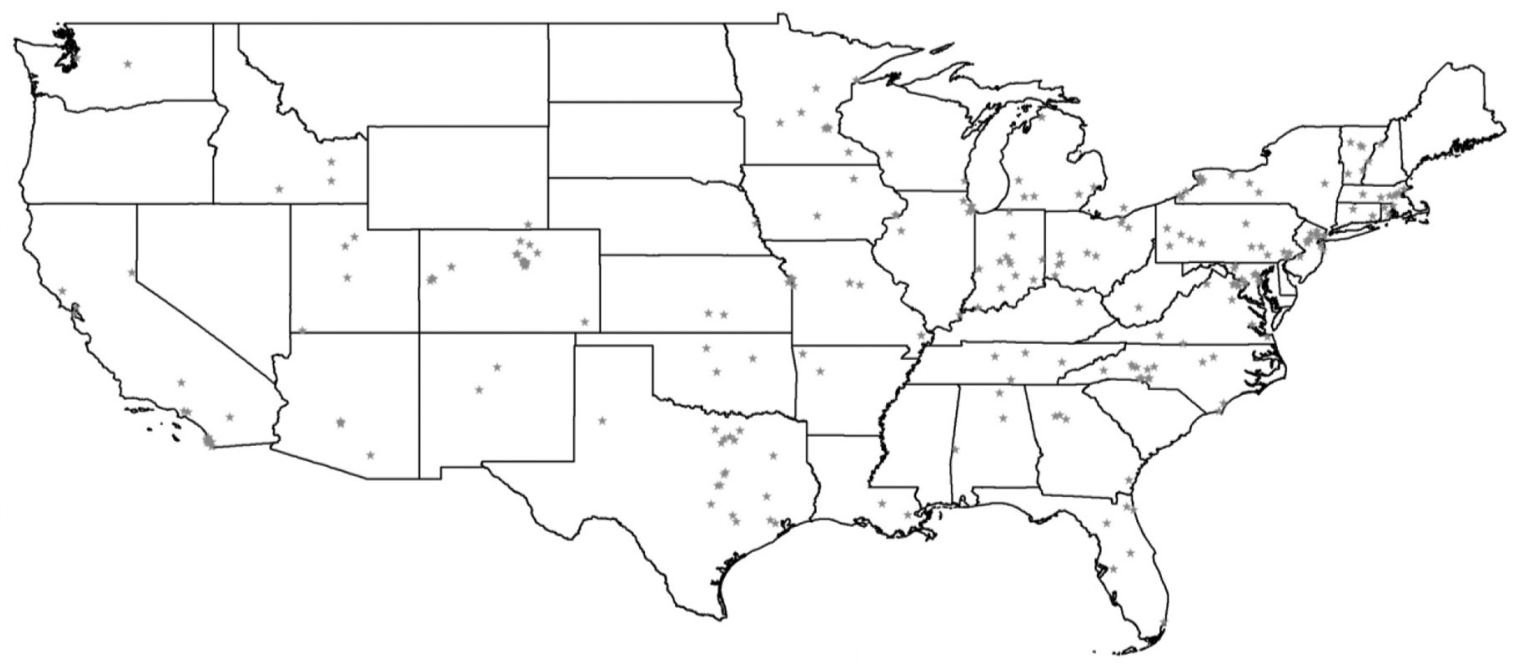

49.0\%) participated in only 1 survey and $7(1.5 \%)$ participated in all 12 (Figure 1). Figure 2 shows the location of 268 respondents (193 have missing locations). The majority ( $\mathrm{n}=312 ; 67.7 \%)$ of the respondents were from family medicine, 20 (4.3\%) were from an "other" specialty, 8 (1.7\%) were from behavioral health, 7 (1.5\%) were from general internal medicine, $4(0.9 \%)$ were from emergency medicine, and $1(0.2 \%)$ was from dental. In total, 109 (23.6\%) were missing a specialty (Table 1$)$. The respondents came from a variety of practice types including primary care only $(\mathrm{n}=132 ; 28.6 \%)$ and multi-specialty groups $(\mathrm{n}=34 ; 7.4 \%$; Table 1$)$. The practices had an average of 26.6 clinicians, with a minimum of 1 clinician and a maximum of 1500 .

Summarized responses to the weekly openended financial impact question are described below. We included the most prominent themes discussed by respondents. The broad categories, that is, financial strain, patient visits, staffing, and telehealth (video and audio) were, in general, consistently reported from week to week.

\section{Financial Strain}

Respondents consistently commented on financial strain throughout the 12 weeks. Decreased revenue

Table 2. Weekly Survey Distribution Details

\begin{tabular}{|c|c|c|c|}
\hline Weekly Survey & $\begin{array}{l}\text { Survey Distribution and } \\
\text { Close Dates* }\end{array}$ & $\begin{array}{c}\text { Survey } \\
\text { Respondents (N) }\end{array}$ & $\begin{array}{l}\text { Respondents Who Answered } \\
\text { the Financial Impact Question }(\mathrm{N})\end{array}$ \\
\hline Week 1 & March 27 to 30 & 186 & 145 \\
\hline Week 2 & April 3 to 6 & 114 & 93 \\
\hline Week 3 & April 10 to 13 & 176 & 131 \\
\hline Week 4 & April 17 to 20 & 125 & 89 \\
\hline Week 5 & April 24 to 27 & 101 & 81 \\
\hline Week 6 & May 1 to 4 & 96 & 79 \\
\hline Week 7 & May 8 to 11 & 80 & 65 \\
\hline Week 8 & May 15 to 18 & 68 & 58 \\
\hline Week 9 & May 22 to 25 & 75 & 66 \\
\hline Week 10 & May 29 to June 1 & 82 & 66 \\
\hline Week 11 & June 5 to 8 & 63 & 52 \\
\hline Week 12 & June 12 to 15 & 65 & 57 \\
\hline Total & & $1231^{\dagger}$ & $982^{\dagger}$ \\
\hline
\end{tabular}

*Close dates in 2020.

${ }^{\dagger}$ Respondents include those that answered this question in multiple surveys. 
Table 3. Number of Responses by Categories Based on Weekly Results

\begin{tabular}{|c|c|c|c|c|c|c|c|c|c|c|c|c|}
\hline & $\begin{array}{c}\text { Week } \\
1\end{array}$ & $\begin{array}{c}\text { Week } \\
2\end{array}$ & $\begin{array}{c}\text { Week } \\
3\end{array}$ & $\begin{array}{c}\text { Week } \\
4\end{array}$ & $\begin{array}{l}\text { Week } \\
5\end{array}$ & $\begin{array}{c}\text { Week } \\
6\end{array}$ & $\begin{array}{l}\text { Week } \\
7\end{array}$ & $\begin{array}{c}\text { Week } \\
8\end{array}$ & $\begin{array}{l}\text { Week } \\
9\end{array}$ & $\begin{array}{c}\text { Week } \\
10\end{array}$ & $\begin{array}{c}\text { Week } \\
11\end{array}$ & $\begin{array}{c}\text { Week } \\
12\end{array}$ \\
\hline Patient visits & 87 & 45 & 61 & 40 & 38 & 38 & 27 & 28 & 35 & 28 & 24 & 23 \\
\hline Financial strain & 26 & 16 & 17 & 11 & 28 & 30 & 37 & 31 & 43 & 43 & 35 & 38 \\
\hline Staffing & 23 & 20 & 22 & 33 & 26 & 20 & 22 & 16 & 12 & 19 & 10 & 18 \\
\hline Video (telehealth) & 45 & 20 & 33 & 24 & 22 & 9 & 9 & 8 & 5 & 9 & 4 & 7 \\
\hline $\begin{array}{l}\text { Audio-only } \\
\text { (telehealth) }\end{array}$ & 12 & 4 & 7 & 6 & 10 & 5 & 1 & 3 & 1 & 1 & 2 & 2 \\
\hline
\end{tabular}

and its immediate and long-term effects were primary concerns.

\section{Lost Revenue}

Respondents referred to decreased revenue in relation to low patient visits, resulting in economic losses. With patient visits down, and many respondents unable to perform usual in-person, billable work, such as routine physicals, immunizations, acute care, and complex disease management, opportunities to bring in income were not available. At the beginning of the pandemic, telehealth reimbursements were low in comparison to in-person visits and organizations initially lost revenue over reimbursement differences. Also, the inability to perform hospital outpatient or ancillary services, for example, laboratory, radiology imaging, respiratory services, affected overall revenue.

\section{Continued Costs and Additional Expenses}

In the first few weeks, respondents implemented staffing changes, office closures, and financial assistance, such as loan applications as immediate financial cost-cutting measures. Some respondents considered approaches like combining practices, deferring loans, bankruptcy, and closing satellite (or main) practices to contain costs. At the same time, respondents noted increased expenses, specifically for personal protective equipment and disinfectants. For those who implemented telehealth, extra costs for initial purchase, training, and expansion were discussed as well.

\section{Financial Help}

By week 3, of the respondents who specifically addressed reduced revenue implications, a portion had applied for provider relief funds. In the following weeks (week 7 through week 12), those who received federal funds reported the sums provided immediate relief.

Respondents acknowledged that it was difficult to know what the "new normal" would look like and how new circumstances would affect the future.

Exemplary quote: "As previously noted, in a feefor-service practice, lower patient volume means less money. As we never made much anyway, the PPP loan [Paycheck Protection Program] (presuming 100\% forgiveness) and the initial Provider Relief Fund (PRF) grant, probably kept us afloat. We will see what happens in another 26 days. If the second pandemic wave does not prompt another, similar round of federal support, then we'll probably be toast." 4

\section{Patient Visits}

Each week, respondents reported on patient visits and discussed the direct relationship between patient visits and revenue, that is, decreased visits equated to decreased revenue.

\section{Extensive Decreases in Patient Visits}

Respondents reported extensive decreases in patient visits, in turn, causing sharp reductions in revenue and difficulty paying operational expenses. Respondents reported a range of decreased in-office visits, and many cited at least $50 \%$ below normal scheduling levels. Some offices allowed the continuation of routine care for non-COVID-19 patients, such as well childcare visits and obstetric care, while others moved to remote appointments only. Low patient volume was attributed to factors such as cancellations (prompted by stay-at-home orders, fear of disease transmission, etc), changes to patient panel (eg, students left campus), and no offerings of elective procedures.

Even though patient visits persisted well below pre-COVID-levels throughout the 12 weeks of survey data, in week 5 a handful of respondents 
Table 4. Staffing Tactics Used to Cut Costs

\begin{tabular}{l} 
Staffing Tactics Used to Cut Costs \\
\hline Reduce hours \\
Reduce salary \\
Implement layoffs \\
Use furloughs for physicians, staff, and/or owners \\
Allow employees to work part-time to qualify for \\
unemployment depending on the state \\
Redirect providers to inpatient care (or other areas where there \\
could be more demand) \\
See more patients per day to make up lost revenue, cross-train \\
and transfer staff to areas that have high demand and need \\
extra support (eg, inpatient care) \\
Omit physician bonus and incentive pay, and not pay hazard \\
pay \\
Pause contributions to retirement benefits \\
Keep mid-level professionals (less expensive than experienced \\
staff) \\
Incorporate hiring freezes \\
Offer voluntary time off without pay \\
Direct employees to use paid time off
\end{tabular}

denoted patient visits had either steadied or increased due to telehealth deployment and expansion. Most respondents had not returned to preCOVID visit levels by 12 weeks.

\section{Potential Barriers for Increasing and Maintaining Patient Visits}

Respondents voiced concern about future patient visits, specifically concerns about patients' willingness to return to in-person care. Also, respondents discussed that as organizations prepared for increased patient visits, extra precautions needed to be considered and some were unsure how to make accommodations for COVID-19 while growing and maintaining high volumes.

Exemplary quote: "Practice is starting to pick up. I will not be as far in the hole in May as I was in April. I am still trying to figure out how we can get back to 22 to 24 patients a day given all the restrictions we need in place for COVID."19

\section{Staffing}

Respondents repeatedly described staffing changes as modes to minimize expenses and the result of staffing changes on care delivery.

\section{Staffing Change Tactics}

In response to decreased revenues, respondents mentioned several staffing changes to cut costs (Table 4).
Exemplary quote: "Significant impact with resulting furloughs of employees at all levels of operations. $30 \%$ reduction in payroll to medical providers and $40 \%$ for management (c-suite). Temporary closure and combining of clinic sites to conserve resources and cut overhead. Decrease of surgical services and elective procedures. Consolidation of rehab services. Suspension of group educational in-person training. "25

Starting in week 9, results differentiated from previous weeks' data because some respondents mentioned restoring staff, not just the continuation of staffing reductions.

A few respondents stated their organization avoided staffing adjustments. In these cases, respondents were usually part of a large health system and could absorb significant financial impact, their organization had reserves to help offset costs, or they had received federal funds to help sustain them, at least for the short term.

\section{Telehealth}

Telehealth categorization includes both video and audio-only care.

\section{Initial Start-up of Telebealth}

The primary reasons for beginning telehealth were to provide patient care, generate revenue, and maintain social distancing. Respondents who were beginning to implement telehealth expressed concerns about startup costs, HIPAA compliance, training, and staff capacity. For those who faced challenges with telehealth start-up, commonly cited barriers were the difficulties with internet connectivity, IT or other staff support, challenges with teaching their patient population, and not having up-to-date technology (both providers and patients). Respondents had concerns regarding reimbursement and whether those virtual visits would translate into financial relief.

Alongside telehealth start-up, audio-only care increased. Respondents reported audio-only visits were more prominent among older and underserved patients.

Exemplary quote: "We are able to do virtual visits, but a lot of patients either do not have the technology to do video visits or cannot make them work or just do not want to be bothered. This results in only being able to do the phone visits and the reimbursement is so much less. ${ }^{26}$ 
The speed of telehealth start-up varied. Some practices were able to ramp up quickly while others required more time. Respondents described a range of activities needed to start-up telehealth implementation; for example, building capabilities, launching platforms, using and slowly expanding utilization. Some considerations involved installation delays due to technical issues, lengthy Electronic Health Record (EHR) integration, and patient learning curves.

As practices introduced telehealth, some respondents mentioned the financial implications of initial implementation, including EHR integration costs, questionable return on investment (depending on patient panel), and time needed for training providers and patients. For audio-only visits, respondents reported increased use to offset declines in in-person visits, as well as not having video capabilities or patient preference for telephone visits. For the first 4 weeks, respondents voiced concerns over telehealth reimbursements for both video and audio-only care. These modes of care were not compensated the same as in-person visits, and in-person visits were not possible for many patients and practices. In addition, some patients preferred using audio-only visits, but the reimbursement rates remained considerably lower than even video visits. Audio-only reimbursement remained a primary concern through week 5 as these visits were non-reimbursable or the reimbursement was a fraction of in-person visits.

\section{Ongoing Implementation of Telehealth}

In weeks 8 through 12, comments highlighted continued utilization of telehealth, resulting in an increase of patients seen. Even with the incorporation of video and audio-only telehealth visits, overall patient visits remained low, in part due to time-consuming activities of scheduling, following-up, and patient training. Ongoing financial concerns were mentioned among a minority of respondents, mainly those who had yet to receive reimbursements. Others expressed uncertainty about long-term sustainability without payment parity.

\section{Discussion}

This study describes the financial pressures primary care clinicians and practices experienced during the beginning stages of the COVID-19 pandemic.
Overall findings contribute to the growing body of literature on COVID-19's impact on primary care. Results show that decreased patient visits directly correlate to decreased revenue, placing immense pressure on primary care clinicians and practices to effectively operate and provide needed care to patients. Policies that contributed to these results include fee-for-service (FFS), Coronavirus Aid, Relief, and Economic Security (CARES) Act, and telehealth reimbursement. First, FFS payment models were detrimental to practices and alternate payment models should be considered. FFS rewards practices based on the number of patients seen rather than the quality of care provided. Alternatives, for example, capitation-based payments, may provide a layer of financial security. ${ }^{31,32}$ One study shows advanced payment models benefit primary care providers and their patients through better care delivery outcomes. ${ }^{33}$ Second, the CARES $\mathrm{Act}^{34}$ was critical for many practices; therefore, the CARES Act or a similar program should be expanded. For some respondents, immediate financial relief occurred due to this federal funding mechanism and kept many organizations operational. Lastly, telehealth reimbursement parity that is equal to in-person coverage should be implemented and sustained consistently across payers and regions. Centers for Medicare \& Medicaid Services (CMS) loosened regulations to allow video ${ }^{35}$ and audioonly $^{36}$ visits to be covered retroactively at payment parity with in-person visits during this public health emergency. ${ }^{37}$ Telehealth visits have shown to be crucial in delivering care that patients would not have otherwise received, thus directly impacting patient outcomes. ${ }^{38,39}$ Further, telehealth interventions prove to be effective for improving a variety of health outcomes including COVID-19 evaluation and testing, ${ }^{40}$ obstetric and gynecologic care, ${ }^{41}$ and lifestyle changes for coronary artery disease ${ }^{42}$ to name a few.

Our study has limitations. First, our response rate fluctuated throughout the weekly survey distributions. Respondents may have felt survey fatigue or believed that their situation did not change from week to week and therefore did not require repeating the same response. Also, primary care physicians experienced different demands and were under immense stress in the ever-changing pandemic; respondents may not have been able to keep up with weekly survey requests and balancing other needs. Second, due to the nature of the question, 
respondents who chose to answer this question wrote a response within a fill-in-the-blank field. This type of question takes more effort than multiple choice. Therefore, those who responded may have felt more strongly, skewing responses toward a more biased perspective in that their situation may be more severe than those who did not respond. Third, the overall decline in response rate across the survey period limits the generalizability of results. Fourth, due to the time frame, we were not able to delineate cohort differences, for example, independent practices versus large multispecialty practices. While we recognize the importance of collecting and reporting on longitudinal cohort data, a lack of consistent respondents within the given period did not allow for this type of analysis. As we continue to collect survey data beyond the 12 weeks, we hope to report longitudinal cohort data in the future. Finally, these answers are from the perspective of the provider and do not provide actual data on finances.

\section{Conclusion}

This study focused on COVID-19's financial impact on primary care clinicians and practices from March 27 through June 15, 2020. Study findings indicated that patient visits decreased extensively; and, as of mid-June, patient visits volume remained below pre-COVID-19 levels. Low patient visit volume directly resulted in decreased revenues, which in turn, affected staffing decisions. Findings also revealed that primary care clinicians and practices pivoted toward telehealth modalities to address low in-person patient visits and provide the necessary care. Future implications highlight the need for ongoing financial solutions to the COVID-19 pandemic's effect on primary care, including attention to payment reform for primary care service delivery.

To see this article online, please go to: http://jabfm.org/content/ 34/3/489.full.

\section{References}

1. Nicola M, Alsafi Z, Sohrabi C, et al. The socio-economic implications of the coronavirus pandemic (COVID-19): A review. Int J Surg. 2020;78:185-193.

2. Chakraborty I, Maity P. COVID-19 outbreak: Migration, effects on society, global environment and prevention. Sci Total Environ. 2020;728:138882.

3. Cajner T, Crane LD, Decker RA, et al. The U.S. labor market during the beginning of the pandemic recession: a working paper. 2020, Chicago, IL. Accessed June 25, 2020.

4. Bartsch SM, Ferguson MC, McKinnell JA, et al. The potential health care costs and resource use associated with COVID-19 in the United States. Health Aff (Millwood). 2020;39(6):927-935.

5. Cutler D. How will COVID-19 affect the health care economy? JAMA. 2020;323(22):2237-2238.

6. Westfall JM, Strange K, DeVoe J, et al. Coronavirus: Family physicians provide telehealth care at risk of bankruptcy. USA Today. April 7, 2020;Opinion. Accessed July 7, 2020.

7. Etz R, Advisory Group - Larry A. Green Center. Quick COVID-19 Primary Care Weekly Survey, Weeks 1-4. Annals of Family Medicine. 2020. https://deepblue.lib. umich.edu/bitstream/handle/2027.42/154717/PC \%20C19\%20Series\%201-4\%20Nat\%20Exec\% 20Summary.pdf? sequence $=1 \&$ isAllowed=y. Accessed June 24, 2020.

8. Etz R, Advisory Group - Larry A. Green Center. Quick COVID-19 Primary Care Weekly Survey, Weeks 5-6. Annals of Family Medicine. 2020. https:// deepblue.lib.umich.edu/bitstream/handle/2027.42/ 154774/PC\%20C19\%20Series\%205-6\%2 0Nat\% 20Exec\%20Summary\%20with\%20comments.pdf? sequence $=1 \&$ isAllowed $=y$. Accessed June 24, 2020.

9. Etz R, Advisory Group - Larry A. Green Center. Quick COVID-19 Primary Care Weekly Survey, Week 7. Annals of Family Medicine. 2020. https://deepblue.lib. umich.edu/bitstream/handle/2027.42/154865/C19\%20 Series\%207\%20National\%20Executive\%20Summary. pdf? sequence $=1 \&$ isAllowed=y. Accessed June 24, 2020.

10. Etz R, Advisory Group - Larry A. Green Center. Quick COVID-19 Primary Care Weekly Survey, Week 8. Annals of Family Medicine. 2020. https:// deepblue.lib.umich.edu/bitstream/handle/2027.42/ 155024/C19\%20Series\%208\%20National\% 20 Executive\%20Summary.pdf? sequence=1\&isAllowed= y. Accessed June 24, 2020.

11. Etz R, Advisory Group - Larry A. Green Center. Quick COVID-19 Primary Care Weekly Survey, Week 10 + Green Center/PCC Press Release. Annals of Family Medicine. 2020. https://deepblue. lib.umich.edu/bitstream/handle/2027.42/155400/C1 $9 \% 20$ Series $\% 2010 \% 20$ Combined $\% 20$ Survey $\% 20$ and $\% 20$ Press $\% 20$ release.pdf?sequence=1\&isAllowed= y. Accessed June 24, 2020.

12. Etz R, Advisory Group - Larry A. Green Center, Primary Care Collaborative. COVID-19 Patient Primary Care Survey, Series 1 Fielded May 4-11, 2020. Annals of Family Medicine. 2020. https:// deepblue.lib.umich.edu/bitstream/handle/2027.42/ 1555448/C19\%20Patient\%20Series\%201\%20National $\% 20$ Executive\%20Summary\%20with\%20comments. pdf? sequence $=1 \&$ isAllowed $=y$. Accessed June 24, 2020. 
13. Etz R, Advisory Group - Larry A. Green Center, Primary Care Collaborative. Quick COVID-19 Primary Care Weekly Survey, Week 11. Annals of Family Medicine. 2020. https://deepblue.lib.umich.edu/bitstream/ handle/2027.42/155448/C19\%20Patient\%20Series \% 201\%20National\% 20Executive\%20Summary\% 20with\%20 comments.pdf? sequence $=1 \&$ isAllowed $=y$. Accessed June 24, 2020.

14. Etz R, Advisory Group - Larry A. Green Center, Primary Care Collaborative. COVID-19 Patient Primary Care Survey, Series 2 Fielded May 22-25, 2020. https://deepblue.lib.umich.edu/bitstream/ handle/2027.42/155447/C19\%20Series\%2011\% 20National\%20Executive\% 20Summary\%20with $\%$ 20comments.pdf?sequence $=1$ \&isAllowed=y. Accessed June 24, 2020.

15. Etz R, Advisory Group - Larry A. Green Center, Primary Care Collaborative. Quick COVID-19 Primary Care Weekly Survey, Week 12. Annals of Family Medicine. 2020. https://deepblue.lib.umich. edu/bitstream/handle/2027.42/155558/C19\% 20Patient\%20Series\%202\%20National\%20Summary $\% 20$ with $\% 20$ comments.pdf?sequence $=1 \&$ isAllowed= y. Accessed June 24, 2020.

16. Etz R, Advisory Group - Larry A. Green Center, Primary Care Collaborative. COVID-19 Patient Primary Care Survey, Series 3 Fielded June 8, 2020. Annals of Family Medicine. 2020. https://deepblue. lib.umich.edu/bitstream/handle/2027.42/155586/C19\% 20Patient\%20Series\%203\%20National\%20Executive $\% 20$ Summary.pdf?sequence=1\&isAllowed=y. Accessed June 24, 2020.

17. Etz R, Advisory Group - Larry A. Green Center, Primary Care Collaborative. Quick COVID-19 Primary Care Weekly Survey, Week 13. Annals of Family Medicine. 2020. https://deepblue.lib.umich.edu/ bitstream/handle/2027.42/155586/C19\%20Patient \%20Series\%203\%20National\%20Executive \% 20 Summary.pdf? sequence $=1 \&$ isAllowed $=y$

18. M S, H B. Introducing medical anthropology: a discipline in action. Lanham: AltaMira Press; 2011.

19. Wade A, Callen E, Robert Graham Center, Filippi M. COVID-19 Survey Report - Week Nine. Washington, DC2020. COVID-19-9. https://www. graham-center.org/content/dam/rgc/documents/ publications-reports/reports/COVID-19SurveyReport Week9.pdf. Published July 7, 2020. Accessed July 8, 2020.

20. Wade A, Callen E, Robert Graham Center, Filippi M. COVID-19 Survey Report - Week Four. Washington, DC2020. COVID-19-4. https://www.grahamcenter.org/content/dam/rgc/documents/publicationsreports/reports/COVID-19SurveyReportWeek4.pdf. Published June 30, 2020. Accessed July 8, 2020.

21. Wade A, Callen E, Robert Graham Center, Filippi M. COVID-19 Survey Report - Week Eleven. Washington, DC2020. COVID-19-11. https://www. graham-center.org/content/dam/rgc/documents/
publications-reports/reports/COVID-19Survey\% 20ReportWeek11.pdf. Published July 7, 2020. Accessed July 8, 2020.

22. Robert Graham Center, Filippi M, Wade A, Callen E. COVID-19 Survey Report - Week Seven. Washington, DC 2020. Report No.: COVID-19-7. https:// www.graham-center.org/content/dam/rgc/documents/ publications-reports/reports/COVID-19SurveyReport Week7.pdf. Published July 7, 2020. Accessed July 8, 2020.

23. Robert Graham Center, Filippi M, Wade A, Callen E. COVID-19 Survey Report - Week Three. Washington, DC 2020. COVID-19-3. https://www.graham-center. org/content/dam/rgc/documents/publicationsreports/reports/COVID-19SurveyReportWeek3.pdf. Published June 30, 2020. Accessed July 8, 2020.

24. Callen E, Robert Graham Center, Filippi M, Wade A. COVID-19 Survey Report - Week Ten. Washington, DC2020. COVID-19-10. https://www.graham-center. org/content/dam/rgc/documents/publications-reports/ reports/COVID-19SurveyReportWeek10.pdf. Published July 7, 2020. Accessed July 8, 2020.

25. Callen E, Robert Graham Center, Filippi M, Wade A. COVID-19 Survey Report - Week Six. Washington, DC2020. COVID-19-6. https://www.graham-center. org/content/dam/rgc/documents/publications-reports/ reports/COVID-19SurveyReportWeek6.pdf. Published June 30, 2020. Accessed July 8, 2020.

26. Callen E, Robert Graham Center, Filippi M, Wade A. COVID-19 Survey Report - Week Five. Washington, DC2020. COVID-19-5. https://www.graham-center. org/content/dam/rgc/documents/publications-reports/ reports/COVID-19SurveyReportWeek5.pdf. Published June 30, 2020. Accessed July 8, 2020.

27. Callen E, Filippi M, Wade A, Robert Graham Center. COVID-19 Survey Report - Week One. Washington, DC2020. COVID-19-1. https://www.graham-center. org/content/dam/rgc/documents/publications-reports/ reports/COVID-19SurveyReportWeek1.pdf. Published June 30, 2020. Accessed July 8, 2020.

28. Filippi M, Wade A, Callen E, Robert Graham Center. COVID-19 Survey Report - Week Eight. Washington, DC2020. COVID-19-8. https://www.graham-center. org/content/dam/rgc/documents/publications-reports/ reports/COVID-19SurveyReportWeek8.pdf. Published July 7, 2020. Accessed July 8, 2020.

29. Filippi M, Wade A, Callen E, Robert Graham Center. COVID-19 Survey Report - Week Two. Washington, DC2020. COVID-19-2. https://www.graham-center. org/content/dam/rgc/documents/publications-reports/ reports/COVID-19SurveyReportWeek2.pdf. Published June 30, 2020. Accessed July 8, 2020.

30. Filippi M, Wade A, Callen E, Robert Graham Center. COVID-19 Survey Report - Week Twelve. Washington, DC2020. COVID-19-12. https://www.graham-center. org/content/dam/rgc/documents/publicationsreports/reports/COVID-19SurveyReportWeek12. pdf. Published July 7, 2020. Accessed July 8, 2020. 
31. Basu S, Phillips RS, Phillips R, Perterson LE, Landon BE. Primary care practice finances in the United States amid the COVID-19 pandemic. Health Affairs. 2020;0(0):10.1377/hlthaff.2020.00794.

32. Bliss HE, George P, Adashi EY. The primary cares initiative: value-based redesign of primary care. Am J Med. 2020;133(5):528-529.

33. Okeke N, Schmidt C, Alborn S, Kumian E. Implementing value-based primary care delivery in federally qualified health centers. Popul Health Manag. 2020.

34. U.S. Department of Health \& Human Services. CARES Act Provider Relief Fund: For Providers. https://www.hhs.gov/coronavirus/cares-act-providerrelief-fund/for-providers/index.html. Published 2020. Updated 6/19/2020. Accessed 06/25/2020.

35. Medicare Telemedicine Health Care Provider Fact Sheet [press release]. March 17, 2020.

36. Trump administration issues second round of sweeping changes to support U.S. healthcare system during COVID-19 pandemic [press release]. April 30, 2020.
37. COVID-19 emergency declaration blanket waivers for health care providers [press release]. 03/30/ 2020.

38. Hirko KA, Kerver JM, Ford S, et al. Telehealth in response to the COVID-19 pandemic: Implications for rural health disparities. J Am Med Inform Assoc. 2020;27(11):1816-1818.

39. Dewar S, Lee PG, Suh TT, Min L. Uptake of virtual visits in a geriatric primary care clinic during the COVID-19 pandemic. J Am Geriatr Soc. 2020;68(7):1392-1394.

40. Joshi AU, Lewiss RE. Telehealth in the time of COVID-19. Emerg Med J. 2020;37(10):637-638.

41. DeNicola N, Grossman D, Marko K, et al. Telehealth interventions to improve obstetric and gynecologic health outcomes: a systematic review. Obstet Gynecol. 2020;135(2):371-382.

42. Turan Kavradim S, Özer Z, Boz İ. Effectiveness of telehealth interventions as a part of secondary prevention in coronary artery disease: a systematic review and meta-analysis. Scand J Caring Sci. 2020;34(3):585-603. 